\title{
Application of Monte Carlo Simulation Technique to Design Flood Estimation: A case study for the Orara River catchment in New South Wales
}

\author{
$\underline{\text { W.L. Caballero }}^{\text {a }}$ and A. Rahman ${ }^{a}$ \\ ${ }^{a}$ School of Computing, Engineering and Mathematics, University of Western Sydney, New South Wales \\ Email: W.Caballero@uws.edu.au
}

\begin{abstract}
Design of water infrastructure projects such as bridge and embankment require design flood estimation. Ideally, design flood estimation is done using at-site flood frequency analysis. However, in many cases, the flood estimation needs to be done at ungauged locations. Methods often adopted for this task such as index flood, rational and regression-based methods are limited to peak flow estimation. As a result, these methods are not suitable in the estimation of complete streamflow hydrograph. At present, Design Event Approach (DEA) is the method currently recommended in Australia for the estimation of design flood hydrograph. However, this method has serious limitations as it treats the rainfall depth as the only random variable in modelling, while other inputs (e.g. temporal patterns and losses) are kept fixed. Joint Probability Approach (JPA)/Monte Carlo Simulation Technique (MCST) is a holistic approach that has proven to overcome some of the limitations associated with the DEA. However, this method has not been tested to a wider hydrologic and catchment conditions. For wider application of the JPA/MCST, one needs readily available regional design data such as stochastic rainfall duration, temporal patterns and losses in the rainfall runoff modelling. This paper presents regionalisation of the model inputs/parameters (i.e. rainfall duration, inter-event duration, intensity-frequency-duration, temporal patterns, initial loss, continuing loss and runoff routing model storage delay parameter) to the JPA/MCST for the State of New South Wales (NSW).
\end{abstract}

This study uses data from 86 pluviograph stations and six catchments from NSW to regionalise the distributions of the input variables and runoff routing model storage delay parameter for the application with the JPA/MCST. A test catchment (the Orara River) is used to test the applicability of the regionalised JPA/MCST in flood estimation.

In this study, complete storm events are selected from the selected pluviograph stations. The selected complete storms are then analysed to derive rainfall complete storm duration $\left(\mathrm{D}_{\mathrm{CS}}\right)$, inter-event duration (IED), intensity-frequency-duration (IFD) data and temporal patterns (TP). In addition, concurrent rainfall and streamflow events data are used to derive values of initial loss (IL), continuing loss (CL) and runoff routing model storage delay parameter $(k)$. The $\mathrm{D}_{\mathrm{CS}}$, IED, IL, CL and $k$ data are described by probability distributions, in that three goodness-of-fit tests are applied (i.e. the Chi-Squared test, Kolmogorov-Smirnov test and Anderson-Darling test). The fitted probability distributions for these variables are then used to specify the regional stochastic inputs in the application of JPA/MCST in NSW State.

The spatial proximity method is adopted in the regionalisation of the $\mathrm{D}_{\mathrm{CS}}$, IED, IFD and TP data, i.e. a distribution at an arbitrary location is determined by using a number of nearby gauged stations' data. To regionalise $\mathrm{D}_{\mathrm{CS}}$, IED and IFD, data from pluviograph stations within $30 \mathrm{~km}$ from the catchments' centre were considered with the aid of inverse distance weighted averaging method. For the TP data regionalisation, a maximum of 20 nearest pluviograph stations within $200 \mathrm{~km}$ were used. Here, it has been found that $\mathrm{D}_{\mathrm{CS}}$, IED, IL and $k$ data can be approximated by gamma distribution and the CL data by exponential distribution.

These regionalised stochastic inputs have been applied to the Orara River catchment in NSW. The derived flood frequency curves from the regionalised JPA/MCST method have been compared with the results from the DEA; it has been found the adopted method showed better results than the DEA generally. However, it should also be noted here that the applicability of the regionalised JPA/MCST needs to be tested to some additional catchments, which is being carried out as part of the on-going research and will be reported in future publications. Although, the method and design data developed in this study are primarily applicable to the eastern part of NSW, it can be adapted to other States of Australia and other countries.

Keywords: Joint Probability Approach, Monte Carlo simulation, Design Event Approach, regional design data, rainfall runoff modelling 


\section{INTRODUCTION}

Estimation of design flood is a common problem in hydrology. This is ideally done by at-site flood frequency analysis. For ungauged catchments, regional methods such as index flood, rational and regression-based methods are commonly adopted, these are however limited to peak flow estimation. To estimate complete streamflow hydrograph, rainfall-runoff modelling is often required. For this task, Design Event Approach (DEA) is the currently recommended method by Institution of Engineers Australia (1987) in Australian Rainfall and Runoff (ARR 1987) (I. E. Aust., 1987). However, this method has serious limitations as it only considers the rainfall depth as the random variable and ignores the probabilistic behaviour of other model inputs, such as rainfall temporal patterns and initial loss (Hill and Mein 1996).

In recent years, there has been considerable research (such as Heneker et al., 2002; Rahman et al., 2002; Kuczera et al., 2003; Aronica and Candela, 2007; Muncaster and Bishop, 2009; Kjeldsen et al., 2010; Aronica et al., 2012; Charalambous et al., 2013; Svensson et al., 2013) on the development and application of the Joint Probability Approach (JPA)/ Monte Carlo simulation technique (MCST) in design flood estimation. The MCST by Rahman et al. (2002) uses a single storage and non-linear runoff routing model to simulate streamflow hydrographs. Their method is flexible for adoption in practical applications and has shown potential that it can give better estimate of design floods than the existing DEA. The applications of this method to a number of catchments in Victoria and Queensland demonstrated that it can overcome some of the limitations associated with the DEA (Carroll and Rahman, 2004). However, the wider application of the JPA/MCST in Australia needs various inputs to be regionalised. These inputs include rainfall duration, intensity, temporal pattern and losses. This paper presents regionalisation of various input variables, such as rainfall durations, temporal patterns and initial loss using observed rainfall and streamflow data in the State of New South Wales (NSW). In addition, the applicability of the regionalised stochastic input variables is tested to a selected catchment (the Orara River) in NSW.

\section{STUDY AREA AND DATA}

This paper uses pluviograph and streamflow data from the State of NSW. The continuous rainfall data for 86 pluviograph stations (as shown in Figure 1) were obtained from Australian Bureau of Meteorology (BOM). The record lengths of the selected pluviograph stations ranged 30 to 101 years (an average of 45 years). The selected pluviograph stations over the eastern part of NSW (as shown in Figure 1) present a good spatial distribution; however, from far western NSW part, no pluviograph station is selected due to lack of quality data. Thus, the regionalisation procedure presented in this paper can ideally be applied in the eastern part of NSW.

Six catchments were also selected for this study as shown in Figure 1 and

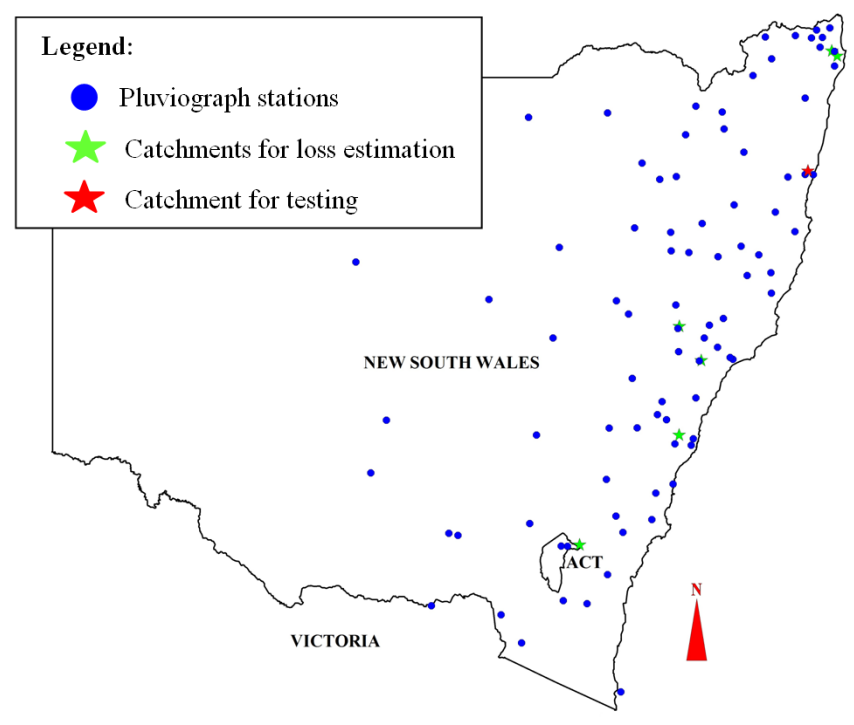

Figure 1. Selected 86 pluviograph stations and seven catchments in New South Wales. listed in Table 1 to regionalise the losses and runoff routing model parameters. A minimum of 21 years of concurrent streamflow and pluviograph records are available for these catchments as can be seen in Table 1. In addition, the Orara River catchment is selected (shown in Figure 1) to test the applicability of the regionalised stochastic input variables using the adopted JPA/MCST. The respective pluviograph station for this test catchment is listed in Table 2, which shows that a minimum of 30 years' of concurrent streamflow and pluviograph records are available for this catchment. 
Table 1. Selected six catchments and pluviograph stations in NSW for estimation of losses

\begin{tabular}{ccccccc}
\hline $\begin{array}{c}\text { Catchment } \\
\text { station ID }\end{array}$ & Station name & $\begin{array}{c}\text { Area } \\
\left(\mathrm{km}^{2}\right)\end{array}$ & $\begin{array}{c}\text { Streamflow } \\
\text { records }\end{array}$ & $\begin{array}{c}\text { Pluviograph } \\
\text { station ID }\end{array}$ & $\begin{array}{c}\text { Pluviograph } \\
\text { records }\end{array}$ & $\begin{array}{c}\text { Concurrent record } \\
\text { length (years) }\end{array}$ \\
\hline 203002 & Coopers Creek at Repentance & 62 & $1976-2009$ & 58072 & $1965-1998$ & 22 \\
203012 & Byron Creek at Binna Burra & 39 & $1977-2009$ & 58072 & $1966-1998$ \\
210068 & Pokolbin Creek at Pokolbin Site 3 & 25 & $1963-2009$ & 61238 & $1962-2011$ & 21 \\
210076 & Antiene Creek at Liddell & 13 & $1968-2010$ & 61212 & $1964-1995$ \\
213005 & Toongabbie Creek at Brien Road & 70 & $1979-2009$ & 67035 & $1965-2001$ & 27 \\
411001 & Mill Post Creek at Bungendore & 16 & $1959-1985$ & 70014 & $1937-2010$ \\
\hline
\end{tabular}

Table 2. Selected catchment and pluviograph station in NSW for testing the applicability of JPA/MCST

\begin{tabular}{ccccccc}
\hline $\begin{array}{l}\text { Catchment } \\
\text { station ID }\end{array}$ & Station name & $\begin{array}{c}\text { Area } \\
\left(\mathrm{km}^{2}\right)\end{array}$ & $\begin{array}{c}\text { Streamflow } \\
\text { records }\end{array}$ & $\begin{array}{c}\text { Pluviograph } \\
\text { station ID }\end{array}$ & $\begin{array}{c}\text { Pluviograph } \\
\text { records }\end{array}$ & $\begin{array}{c}\text { Concurrent record } \\
\text { length (years) }\end{array}$ \\
\hline 204025 & Orara River at Karangi & 135 & $1970-2011$ & 59026 & $1970-2010$ \\
\hline
\end{tabular}

\section{METHODS}

\subsection{Selection of storm events}

In this study, a complete storm (CS) event is used, as defined by Rahman et al. (2002) and Hoang et al. (1999). A CS is defined as the period of significant rain preceded and followed by an arbitrary selected 'dry hours' (e.g. 6 hours) period. Here, the period between the successive selected complete storms, referred to as 'inter-event duration' is used as a random variable. It is defined as the time elapsed in hours between the successive selected complete storm events. To select the appropriate number of complete storm events in the analysis, a threshold rainfall intensity value was adopted following the approach by Rahman et al. (2002), that is $0.40 \times 2$-year average recurrence interval (ARI) design rainfall intensity value for the corresponding rainfall duration. The adopted threshold value, as mentioned above, resulted in selection of 2 to 8 complete storm events on average per year at a given pluviograph station.

\subsection{Regionalisation of various input variables}

In hydrology, regionalisation as defined by Bloschl and Sivapalan (1995) is the method of 'transferring information from a donor gauged catchment to a target ungauged catchment or catchment of interest'. Commonly adopted regionalisation methods, such as by Deckers et al. (2010) is based on the concept of physical similarity, i.e. similarity in catchment characteristics and by Vaze et al. (2011), and Haddad and Rahman (2012) which are based on spatial proximity. This study adopted the spatial proximity method similar to Merz and Bloschl (2004) and Parajka et al. (2005). The initial loss and continuing loss model is adopted in this study in the generation of rainfall excess hyetograph. The initial loss in this model is defined as the amount of rainfall that occurs before the start of the surface runoff; while the continuing loss is the average loss rate throughout the remainder of the rainfall event. In this study, the JPA/MCST considers seven input variables as random variables: complete storm duration $\left(\mathrm{D}_{\mathrm{CS}}\right)$, inter-event duration (IED), rainfall intensity in the form of intensity-frequency-duration (IFD), temporal patterns (TP), initial loss (IL), continuing loss (CL) and runoff routing model's storage delay parameter $(k)$. Therefore, in this study, seven input variables need to be regionalised from the recorded pluviograph and streamflow data of the selected catchments and pluviograph stations in NSW.

This study adopted a parametric approach to specify probability distribution, where the distributions of $\mathrm{D}_{\mathrm{CS}}$, IED, IL, CL and $k$ by are expressed by probability distributions. Here, the observed data is fitted with a given probability distribution and the degree of fit is assessed by applying three goodness-of-fit tests: Chi-Squared (C-S) test, Kolmogorov-Smirnov (K-S) test and Anderson-Darling (A-D) test. The test is applied at 5\% level of significance to examine the statistical hypothesis that the data follow a hypothesised probability distribution. Two distributions (exponential and gamma) as adopted by Haddad and Rahman (2011) and Carroll and Rahman (2004) are adopted in this study as the candidate distributions. In addition, from the selected pluviograph stations, non-dimensional TP data (expressed in 10 time intervals and cumulative proportion of rainfall depth) for all the selected complete storms are pooled together to create a regional TP database. 
The regionalisation of the $\mathrm{D}_{\mathrm{CS}}$, IED, IFD and TP data is undertaken by using spatial proximity method (as mentioned above) with the aid of inverse distance weighting method (as reported in Caballero et al., 2011). Here, all the pluviograph stations within $30 \mathrm{~km}$ radius from the centre of the catchment of interest are adopted to regionalise the IFD data. To regionalise the TP data, a maximum of 20 nearest pluviograph stations within a $200 \mathrm{~km}$ radius are used to capture the inherent variability of the TP data in the application of JPA/MCST. Here, the non-dimensional TPs are pooled together from the selected pluviograph stations for random sampling during the simulation.

\subsection{Adopted Monte Carlo simulation technique (MCST)}

To derive datasets of IL, CL and $k$ values, the selected catchments shown in Tables 1 and 2 are calibrated using the runoff routing model of the following form:

$S=k Q^{m}$

where $S$ is the catchments' storage $\left(\mathrm{m}^{3}\right), k$ is the runoff routing model storage delay parameter in hours (h), $Q$ is the discharge at the catchments' outlet $\left(\mathrm{m}^{3} / \mathrm{s}\right)$ and the non-linearity parameter $(\mathrm{m})$, which is adopted as 0.8 in this application. A single storage concentrated at the catchment outlet was considered in the adopted model. The applicability of the single storage runoff routing model is justified given that the selected catchments are not very large $\left(13 \mathrm{~km}^{2}\right.$ to $70 \mathrm{~km}^{2}$ as indicated in Table 1). Here, direct runoff needs to be separated from baseflow before the calibration of the runoff routing model. This is achieved by using baseflow separation method proposed by Boughton (1988). A surface runoff threshold value equal to 0.01 $\mathrm{mm} / \mathrm{h}$ is also adopted in the estimation of an IL, similar to Hill and Mein (1996).

In the application of the MCST to the test catchment (Table 2), values of $\mathrm{D}_{\mathrm{CS}}$, IED, IFD, TP, IL, CL and $k$ were simulated (considering their correlations where possible) from the respective probability distributions for the catchment of interest to form streamflow hydrographs. For simulating the TP, the regional pooled TP database was sampled randomly (based on the generated $\mathrm{D}_{\mathrm{CS}}$ ). The resulting numbers of pluviograph stations for different distances for the Orara River catchment are displayed in Table 3. More detailed steps with the adopted method can be found in Caballero and Rahman (2013).

\section{MODEL EVALUATION}

To evaluate the model, the flood quantiles estimated from the JPA/MCST based on Table 3. Number of pluviograph stations to derive TP data the regionalised model input/parameter

\begin{tabular}{ccccc}
\hline \multirow{2}{*}{$\begin{array}{c}\text { Catchment } \\
\text { station ID }\end{array}$} & \multicolumn{4}{c}{ Distances from catchment centre and number of stations } \\
\cline { 2 - 5 } & $30 \mathrm{~km}$ & $50 \mathrm{~km}$ & $100 \mathrm{~km}$ & $200 \mathrm{~km}$ \\
\hline 204025 & 3 & 3 & 5 & 25 \\
\hline
\end{tabular}

values and the currently recommended DEA are compared against the at-site flood frequency analysis (FFA) estimates for the selected test catchment (Table 2). The at-site observed annual maximum (AM) flood series data are fitted by the Bayesian-Log-Pearson Type 3 distribution to obtain FFA estimates using FLIKE software (Kuczera, 1999). The 90\% confidence limits are also computed for the at-site FFA curves from FLIKE. In the DEA analysis adopted in this paper, the design rainfall intensity data at the test catchment sites are obtained from Australian Bureau of Meteorology (BOM) website following the approach of ARR1987 (I. E. Aust., 1987). The adopted values of IL, CL and $k$ are taken as the median values from the calibration of the adopted runoff routing model using the selected rainfall and streamflow events data. The design TP data from ARR 1987 are used in the adopted DEA reported in this paper.

\section{RESULTS}

A total of 19,718 complete storm events were selected from the 86 pluviograph stations in the State of NSW based on the criteria set in Section 3.1. On average, 229 events (range: 65 to 622 events) per station were selected from a pluviograph station. This means that 5 events per year were selected from each station.

From the selected complete storm events, the average value of the $\mathrm{D}_{\mathrm{CS}}$ data is 26 hours (range: 14 to 55 hours). The regional average values of the mean and standard deviation of the $\mathrm{D}_{\mathrm{CS}}$ data are 26 hours and 22 hours, respectively. Based on the three goodness-of-fit tests, gamma distribution shows better fit than the exponential distribution for the majority of the selected 86 stations. The test results are as follows: C-S test, $15 \%$ and $28 \%$; K-S test, $50 \%$ and $76 \%$; A-D test, $51 \%$ and $79 \%$. Based on these tests, it appears that the C-S test results are remarkably different than those of the K-S and A-D tests. The C-S test rejected about $75 \%$ of the stations which appeared to be unreasonable when compared with the two other test results, and hence, the $\mathrm{C}-\mathrm{S}$ test results were ignored. Overall, the gamma distribution provided a better fit. Here, the $\mathrm{D}_{\mathrm{CS}}$ data can be 
represented by gamma distribution for about $80 \%$ of the selected stations. Therefore, this study adopted the gamma distribution to regionalise the $\mathrm{D}_{\mathrm{CS}}$ data in the application of the proposed MCST.

The IED data corresponding to the selected complete storm events range from 42 to 148 days with an average of 70 days. The mean and standard deviation of the IED data are 70 days and 83 days, respectively. The K-S and A-D tests indicated that gamma distribution fits $79 \%$ and $78 \%$ of the selected stations' IED data, respectively. Similar to the test of $\mathrm{D}_{\mathrm{CS}}$ data, the C-S test result was also ignored as it rejected about $73 \%$ of the stations which appeared to be unreasonable when compared with the two other test results. Finally, this study adopted the gamma distribution to specify the distribution of the IED data in the application of the proposed MCST.

Following the approach similar to Rahman et al. (2002), the IFD table was developed for each of the selected 86 pluviograph stations. Using the IDW averaging method, the IFD data for the Orara River catchment were obtained using the at-site IFD curves from a number of nearby pluviograph stations. For example, the regional IFD data were obtained by applying IDW method using the individual IFD curves of pluviograph stations 59026 (located within the catchment), 59040 and 59067, with distances of 3.46, 13.67 and $25.68 \mathrm{~km}$ from the centre of the catchment, respectively. The regional TPs were developed based on the nearest 20 pluviograph stations for the Orara River catchment as shown in Table 3.

A total of 346 events were finally selected to estimate the IL, CL and $k$ values as shown in Table 4 . The goodness-of-fit tests were used to regionalise the IL, CL and $k$ data using the exponential and gamma distributions. For the IL, the study found that the gamma distribution fitted the observed IL data of the six catchments better than the exponential distribution which only fitted five catchments. Similar results were found after combining the IL data for all the six catchments, and thus the gamma distribution was adopted to specify the IL data.

For CL data, both the gamma and exponential distributions provided a similar acceptable fit based on the K-S and A-D tests; both showed a fit for the $83 \%$ of the catchments. After combining the CL data for all the six catchments, these two distributions again showed similar test results which implied that the CL data could be described by either exponential or gamma distribution; however, exponential distribution was adopted since it is simpler than the gamma distribution.

Table 4. selected events after the calibration

\begin{tabular}{ccccc}
\hline $\begin{array}{c}\text { Catchment } \\
\text { station ID }\end{array}$ & $\begin{array}{c}\text { Concurrent } \\
\text { record length } \\
\text { (years) }\end{array}$ & $\begin{array}{c}\text { Total } \\
\text { events for } \\
\text { calibration }\end{array}$ & $\begin{array}{c}\text { Number of } \\
\text { events after } \\
\text { calibration }\end{array}$ & $\begin{array}{c}\text { Average of } \\
\text { events per } \\
\text { year }\end{array}$ \\
\hline 203002 & 22 & 25 & 13 & 1 \\
203012 & 21 & 25 & 18 & 1 \\
210068 & 46 & 140 & 29 & 3 \\
210076 & 27 & 41 & 10 & 2 \\
213005 & 22 & 37 & 16 & 2 \\
411001 & 26 & 78 & 22 & 3 \\
Total & $\mathbf{1 6 4}$ & $\mathbf{3 4 6}$ & $\mathbf{1 0 8}$ & \\
Average & $\mathbf{2 7}$ & $\mathbf{4 8}$ & $\mathbf{1 8}$ & \\
\hline
\end{tabular}

For the at-site unstandardised $k$ data, the gamma distribution provided a better fit for all the six catchments as compared to the exponential distribution using the K-S and A-D tests. In addition, the at-site $k$ data of the six catchments were standardised since these catchments considered here had different catchment areas. To standardise the values of the at-site $k$ values for a given catchment, individual values were divided by its respective catchment area. The K-S and A-D tests were then applied to the standardised at-site $k$ data and to the combined standardised $k$ data. For the standardised $k$ data, both the exponential and gamma distributions showed a similar fit. However, this study adopted gamma distribution.

In summary, rainfall $\mathrm{D}_{\mathrm{CS}}$, IED, IL and $k$ data were approximated by gamma distribution, while the CL data by exponential distribution. The IFD data was regionalised by using the IFD data of the nearby stations situated within $30 \mathrm{~km}$ radius from the centre of the catchment of interest. The TP data from nearby pluviograph stations (with maximum of 20 stations) with distances up to $200 \mathrm{~km}$ from the centre of the catchment of interest were used as the regional pooled TP database during simulation. These derived regional distributions can be used to generate stochastic input/model parameters at any location in eastern NSW to apply the JPA/MCST for design flood estimation without the need of any primary at-site data analysis.

To simulate the streamflow hydrographs, the regionalised model inputs were adopted in the application of the MCST for the Orara River catchment. In the simulation, each model inputs were generated 30,000 times based on their marginal distributions and using the regionalised IFD and TP data. The simulated data for each of the input variables were used to generate a streamflow hydrograph. A total of 30,000 hydrographs were generated. The peaks of these hydrographs were used to construct the DFFC. The simulated flood peaks were used to construct the DFFC considering the effects of IED as described in Caballero and Rahman (2013). The constructed DFFCs are shown in Figure 2. The DFFCs show reasonable fit for the Orara River catchment. 
For the DEA, Figure 2 showed over-estimation to the Orara River catchment for ARIs up to 10years while under-estimation for ARIs greater than 10 -years. It should be noted here that the atsite flood values (for higher ARIs) have notably larger rating ratio $(R R)$ values $(>>1)$ as shown in Figure 2. Here, RR is the ratio of observed discharge/highest measured discharge at a site as explained in Haddad et al. (2010). Hence, there is a high degree of uncertainty associated with these values of individual flood discharges. Overall, the regionalised JPA/MCST shows a better results than the currently recommended at-site DEA.

\section{CONCLUSIONS}

This study shows that the input/model parameters can be regionalised in the application of the Joint

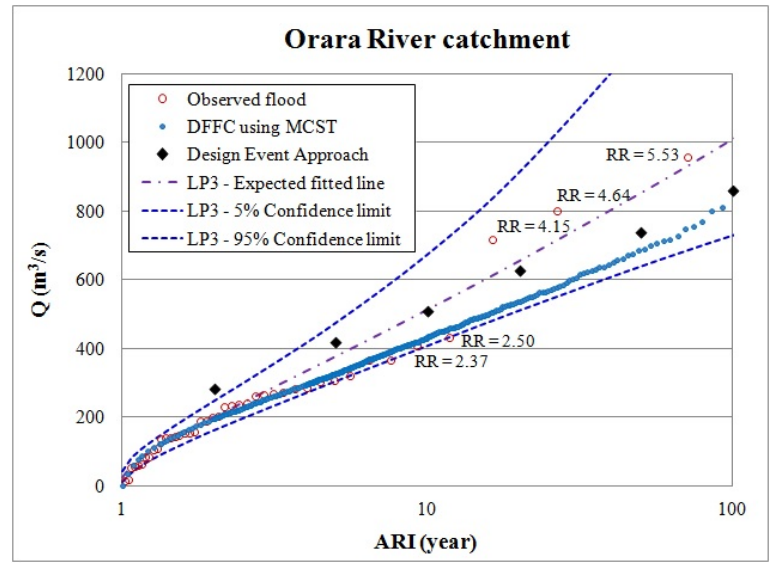

Figure 2. Flood quantiles for the selected test catchment (the Orara River)

Probability Approach (JPA)/Monte Carlo

Simulation Technique (MCST) to be able to apply it easily in practice. It has been found that the distributions of rainfall durations, inter-event durations, initial loss and storage delay parameter of the adopted runoff routing model can be approximated by gamma distribution. The exponential distribution can be used to specify the distribution of continuing loss. By the use of an inverse distance weighted averaging method, the regional rainfall intensities at an ungauged location can be obtained based on the individual IFD tables. For an ungauged location, the developed regional TP database can also be used to obtain stochastic TP.

For estimating design floods for eastern NSW, the regionalised input variables/parameter data derived were applied with the JPA/MCST to the Orara River catchment. In this study, the regionalised JPA/MCST is found to provide more accurate design flood estimates than the currently recommended at-site Design Event Approach. Even though the regionalisation approach adopted with the JPA/MCST in this study is mainly applicable to the eastern NSW, this can easily be adapted to other part of Australian States.

It should be noted here that the applicability of the new method needs to be tested to some additional catchments, which is being carried out as a part of the on-going research and will be reported in future publications

\section{ACKNOWLEDGMENTS}

The authors would like to acknowledge the Australian Bureau of Meteorology for providing the pluviograph data and the NSW Office of Water for streamflow data.

\section{REFERENCES}

Aronica, G.T. and Candela, A. (2007). Derivation of flood frequency curves in poorly gauged Mediterranean catchments using a simple stochastic hydrological rainfall-runoff model. Journal of Hydrology, 347 (1-2), $132-142$.

Aronica, G.T., Franza, F., Bates, P.D. and Neal, J.C. (2012). Probabilistic evaluation of flood hazard in urban areas using Monte Carlo simulation. Hydrological Processes, 26, 3962-3972.

Bloschl, G. and Sivapalan, M. (1995). Scale Issues in Hydrological Modelling: A review. Hydrological Processes, 9(3/4), 251-290.

Boughton, W.C. (1988). Partitioning streamflow by computer. The Institution of Engineers, Australia, Civil Engineering Transactions, 285-291.

Caballero, W.L. and Rahman, A. (2013). Development of regionalised joint probability approach to flood estimation: A case study for Eastern New South Wales, Australia. Hydrological Processes, Published online in Wiley Online Library, 10 pp.

Caballero, W.L., Taylor, M., Rahman, A. and Shrestha, S. (2011). Regionalisation of intensity-frequencyduration data: A case study for New South Wales. $19^{\text {th }}$ International Congress on Modelling and Simulation, Perth, Australia, December 2011, 3775-3781.

Carroll, D.G. and Rahman, A. (2004). Investigation of sub-tropical rainfall characteristics for use in the Joint Probability Approach to design flood estimation. In Proceedings of Second Asia Pacific Association of Hydrology and Water Resources (APHW) Conference, Singapore, July 2004. 
Charalambous, J., Rahman, A. and Carroll, D. (2013). Application of Monte Carlo Simulation Technique to design flood estimation: A case study for North Johnstone River in Queensland, Australia. Water Resources Management, 13 pp.

Deckers, D.L.E.H., Booij, M.J., Rientjes, T.H.M. and Krol, M.S. (2010). Catchment variability and parameter estimation in multi-objective regionalisation of a rainfall-runoff model. Water Resources Management, 24 (14), 3961-3985.

Haddad, K. and Rahman, A. (2011). Regionalisation of storm duration for determining derived flood frequency curve: A case study for Victoria in Australia. Asian Journal of Water, Environment and Pollution, 8 (3), 37-46.

Haddad, K. and Rahman, A. (2012). Regional flood frequency analysis in eastern Australia: Bayesian GLS regression-based methods within fixed region and ROI framework: Quantile Regression vs. Parameter Regression Technique. Journal of Hydrology, 430-431, 142-161.

Haddad, K., Rahman, A., Weinmann, P.E., Kuczera, G. and Ball, J.E. (2010). Streamflow data preparation for regional flood frequency analysis: Lessons from south-east Australia. Australian Journal of Water Resources, 14 (1), 17-32.

Heneker, T.M., Lambert, M.F. and Kuczera, G. (2002). Overcoming the joint probability problem associated with initial loss estimation in design flood estimation. Proceedings of the $27^{\text {th }}$ National Hydrology and Water Resources Symposium, The Water Challenge, Balancing the Risk, I.E. Australia, 20-23 May 2002. CD-ROM Publication. 9 pp.

Hill, P.I. and Mein, R.G. (1996). Incompatibilities between storm temporal patters and losses for design flood estimation. Hydrology and Water Resources Symp., Hobart, Tasmania, Australia, May 1996, 445-451.

Hoang, T.M.T., Rahman, A., Weinmann, P.E., Laurenson, E.M. and Nathan, R.J. (1999). Joint probability descriptions of design rainfalls. International Hydrology and Water Resources Symposium of the I. E. Aust. and $2^{\text {nd }}$ International Conference on Water Resources and Environmental Research, Brisbane, Australia, July 1999, 379-384.

Institution of Engineers Australia (1987). Australian Rainfall and Runoff - A guide to flood estimation. Volumes 1 and 2. Institution of Engineers, Australia.

Kjeldsen, T.R., Svensson, C. and Jones, D.A. (2010). A joint probability to flood frequency estimation using Monte Carlo simulation, Proceedings of the BHS Third International Symposium: Role of Hydrology in Managing Consequences of a Changing Global Environment, Newcastle University, Newcastle Upon Tyne, United Kingdom, July 2010, 11 pp.

Kuczera, G. (1999). Comprehensive at-site flood frequency analysis using Monte Carlo Bayesian inference. Water Resources Research, 35 (5), 1551-1558.

Kuczera, G., Lambert, M.F., Heneker, T.M., Jennings, S., Frost, A. and Coombes, P. (2003). Joint Probability and Design Storms at the Crossroads. Keynote paper. $28^{\text {th }}$ International Hydrology and Water Resources Symposium, Institution of Engineers Australia, Wollongong, Australia, 11-13 November 2003.

Merz, R. and Bloschl, G. (2004). Regionalisation of catchment model parameters. Journal of Hydrology, 287, 95-123.

Muncaster, S.H. and Bishop, W.A. (2009). Flood estimation in urban catchments with RORB - Monte Carlo Simulation - Use of local historical pluviographic data. $32^{\text {nd }}$ Hydrology and Water Resources Symposium, Newcastle, Australia, 30 November - 3 December 2009.

Parajka, J., Merz, R. and Bloschl, G. (2005). A comparison of regionalization methods for catchment model parameters. Hydrology and Earth System Sciences, 9 (3), 157-171.

Rahman, A., Weinmann, P.E., Hoang, T.M.T., Laurenson, E.M. (2002). Monte Carlo simulation of flood frequency curves from rainfall. Journal of Hydrology, 256 (3-4), 196-210.

Svensson, C., Kjeldsen, T.R. and Jones, D.A. (2013). Flood frequency estimation using a joint probability approach within a Monte Carlo framework. Hydrological Sciences Journal, 58 (1), 8-26.

Vaze, J., Perraud, J.M., Teng, J., Chiew, F. and Wang, B. (2011). Estimating regional model parameters using spatial land cover information - implications for predictions in ungauged basins. $19^{\text {th }}$ International Congress on Modelling and Simulation, Perth, Australia, December 2011, 3433-3440. 